BRUNA ARAUJO OZANAN

\section{EFICÁCIA PRECLUSIVA DA COISA JULGADA}

Dissertação apresentada à Banca Examinadora do Programa de Pós-Graduação em Direito, da Faculdade de Direito da Universidade de São Paulo, como exigência parcial para obtenção do título de Mestre em Direito, na área de concentração Direito Processual Civil, sob a orientação do Prof. Doutor Walter Piva Rodrigues.

UNIVERSIDADE DE SÃO PAULO

FACULDADE DE DIREITO

São Paulo-SP

2018 
Ficha Catalográfica

Faculdade de Direito da Universidade de São Paulo

Ozanan, Bruna Araujo

Eficácia preclusiva da coisa julgada / Bruna Araujo Ozanan. - São Paulo: USP / Faculdade de Direito, 2018.

$145 f$.

Orientador: Professor Doutor Walter Piva Rodrigues

Dissertação (Mestrado), Universidade de São Paulo, USP, Programa de Pós-Graduação em Direito, Direito Processual, 2018.

1. Regra da Eventualidade. 2. Preclusão. 3. Coisa Julgada. 4. Limites Objetivos da Coisa Julgada. 5. Eficácia Preclusiva da Coisa Julgada. I. Rodrigues, Walter Piva. II. Título. 


\section{OZANAN, Bruna Ozanan}

Título: Eficácia preclusiva da coisa julgada

Dissertação apresentada à Banca Examinadora do Programa de Pós-Graduação em Direito, da Faculdade de Direito da Universidade de São Paulo, como exigência parcial para obtenção do título de Mestre em Direito, na área de concentração Direito Processual Civil.

Orientador: Prof. Doutor Walter Piva Rodrigues

Aprovada em:

Banca Examinadora

Prof. Dr. Instituição:

Julgamento: Assinatura:

Prof. Dr Instituição:

Julgamento: Assinatura:

Prof. Dr. Instituição:

Julgamento: Assinatura: 
Aos meus pais, SONIA e ANTONIO, meus maiores exemplos, que me ensinaram todos os valores éticos e morais em que me apoio hoje, que me deram força para enfrentar as mais diversas situações da vida e que me amam incondicionalmente.

Ao meu marido, RAUL, pelo apoio, paciência, amor, companheirismo e compreensão.

Ao meu filho, LEONARDO, que me ensina todos os dias a ser uma pessoa melhor, que não me faz desistir dos meus sonhos e que me ensinou o verdadeiro significado do mais puro amor. 


\section{AGRADECIMENTOS}

Agradeço a minha família por não me deixar desistir nos momentos difíceis. Obrigada por acreditarem em mim e me apoiarem sempre.

Agradeço ao meu colega e Mestre MARCUS ViniciUs DA COSTA FERnANDES por ter me ensinado os verdadeiros valores da nossa profissão, por ter me mostrado que a advocacia é arte e sacerdócio e, por isso, temos sempre que seguir em frente, fortes, incansáveis e crentes na Justiça. Obrigada por ter me inspirado a gostar tanto de Processo Civil.

Meus sinceros agradecimentos ao meu orientador, WALTER PIVA RodRIGUES, por ter me aceitado como sua orientanda, ter acreditado em mim, me ajudado na escolha do tema de dissertação e por toda a disponibilidade que me foi dedicada.

Por fim, agradeço aos Professores RicARDo DE BARRos LEONEL e RENNAN THAMAY, por todas as reuniões, dicas, ensinamentos e orientações. 
OZANAN, Bruna Araujo. A eficácia preclusiva da coisa julgada. 2018. 145f. Dissertação (Mestrado em Direito) - Faculdade de Direito, Universidade de São Paulo, São Paulo, 2018.

\section{RESUMO}

A coisa julgada é o instituto que confere segurança a todas as relações jurídicas levadas à apreciação do Poder Judiciário. A coisa julgada confere imunização da decisão prolatada pelo Poder Judiciário. A imperatividade, como sendo uma característica fundamental da tutela jurisdicional prestada pelo Estado, somente tem vigência plena se o que foi decidido não puder ser alterado por decisão ulterior. Todavia, a proteção conferida pela coisa julgada não pode ser maior do aquilo que foi efetivamente decidido (res judicanda), cujos limites encontram-se dentro da lide. Assim, somente a parte que altera a realidade dos sujeitos do processo tem importância para a estabilização da coisa julgada, que é o dispositivo do julgado. Mas, a fundamentação que levou o Poder Judiciário a chegar às suas conclusões não é atingida pela autoridade da coisa julgada. A fundamentação tem íntima relação com a causa de pedir do autor e a causa excipiendi do réu. Assim, se fosse permitido que novos argumentos que tivessem o condão de alterar a causa de pedir fossem deduzidos em nova demanda, ainda que não deduzidos na primeira demanda, o ordenamento jurídico seria reduzido a uma enorme insegurança jurídica. $\mathrm{O}$ presente trabalho tem como finalidade enfrentar qual matéria do primeiro processo é irrelevante para ulteriores discussões, mesmo que não alegadas. Por isso, para a correta compreensão do instituto da eficácia preclusiva da coisa julgada, se faz necessário analisar (i) os institutos jurídicos correlatos, quais sejam a coisa julgada e a preclusão; (ii) os limites objetivos da coisa julgada (iii) a posição do problema imposto pela redação do art. 508 do Código de Processo Civil e, com ele, a divergência doutrinária e jurisprudencial existente sobre qual seria o real alcance dos efeitos da eficácia preclusiva da coisa julgada; (iv) qual a solução que deve ser dada a fim de se aplicar corretamente o instituto da eficácia preclusiva da coisa julgada; (v) qual a área de atuação e quais as questões que estão sujeitas à eficácia preclusiva da coisa julgada; (vi) a eficácia preclusiva da coisa julgada como uma forma de impedir que outras demandas incompatíveis com a decisão transitada em julgado sejam propostas e, por fim, (vi) o tratamento dado à eficácia preclusiva da coisa julgada no novo Código de Processo Civil (Lei n. 13.105/2015).

Palavras-chave: Regra da eventualidade. Preclusão. Coisa julgada. Limites objetivos da coisa julgada. Eficácia preclusiva da coisa julgada. 
OZANAN, BRUNA ARAUJO. The preclusive coming into force of res judicata. 2018. 145p. Master's Thesis - Faculty of Law, University of São Paulo, São Paulo, 2018.

\begin{abstract}
The res judicata is the institute that provides security to all legal relationships brought to the consideration of the Judicial Power. The res judicata provides immunization for the decision handed down by the Judiciary. The mandatory, as a fundamental characteristic of the jurisdiction provided by the state, only has full validity if what was already decided cannot be changed by subsequent decision. However, the protection afforded by the res judicata cannot be bigger than what was actually decided (res judicanda), whose boundaries are contained within the dispute itself. Thus, only the part that changes the reality of the subjects of the process is important for the stabilization of res judicata, which is the dispositive. But, the reasons that led the Judiciary to come to their conclusions are not reached by the authority of res judicata. The fundaments have close relation to the causa petendi of the author and the causa excipiendi of the defendant. If it was allowed that new arguments, that have the power to change the causa petendi, could be deducted in new demand, since not deducted in the first demand, the legal system would be reduced to a huge legal unsafety. This study aims to present what material of the first process is irrelevant for further discussion, even if not alleged. Therefore, for a correct understanding of the Preclusive coming into force of res judicata, it is necessary to examine (i) others related legal institutions, which are res judicata and preclusion; (ii) objective limits of res judicata; (iii) the position of the problem posed by the wording of the text of the art. 508 of the Civil Procedure Code, and, with it, the doctrinal and jurisprudential divergence exists on what would be the real scope of the Preclusive coming into force of res judicata; (iv) which solution should be given in order to correctly apply the Preclusive coming into force of res judicata; (v) what area of expertise and what issues are subject to the Preclusive coming into force of res judicata; (vi) the Preclusive coming into force of res judicata judged as a way to prevent other demands incompatible with the final decision being proposed and, finally, (vii) the treatment given to the Preclusive coming into force of res judicata by the new Code of Civil Procedure ( law n. 13.105/2015).
\end{abstract}

Keywords: Principle of eventuality. Preclusion. Res judicata. Objective limits of res judicata. Preclusive coming into force of res judicata. 


\section{SUMÁRIO}

1 PREMISSAS NECESSÁRIAS AO EXAME DO TEMA .............................................. 13

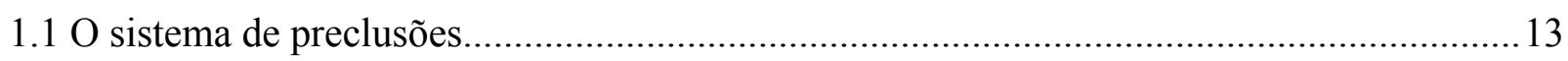

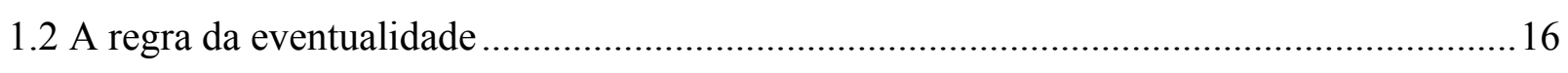

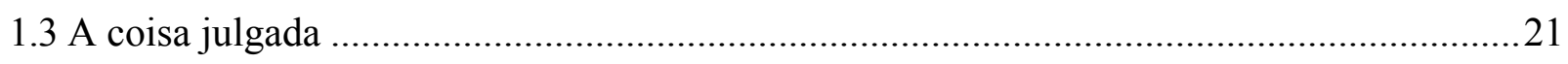

1.3.1 A coisa julgada formal e a coisa julgada material ................................................28

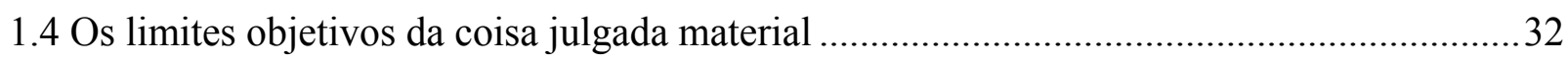

1.4.1 Os limites objetivos da coisa julgada material e as questões prejudiciais no

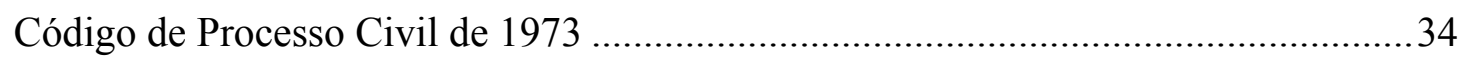

1.4.2 Os limites objetivos da coisa julgada material e as questões prejudiciais no atual Código de Processo Civil.

1.4.3 Os limites objetivos da coisa julgada material e a eficácia preclusiva da coisa julgada

\section{A EFICÁCIA PRECLUSIVA DA COISA JULGADA}

$2.1 \mathrm{O}$ conceito da eficácia preclusiva na Teoria Geral do Direito...........................................53

$2.2 \mathrm{O}$ conceito da eficácia preclusiva da coisa julgada material ................................................55

2.3 A eficácia preclusiva da coisa julgada e o julgamento implícito .........................................58

2.4 A eficácia preclusiva da coisa julgada no ordenamento jurídico .......................................61

2.4.1 A eficácia preclusiva da coisa julgada no Código de Processo Civil de 2015 (Lei

n. 13.105/2015)

2.4.1.1 A eficácia preclusiva da coisa julgada em matéria de direito de concorrência na nova lei do CADE (Lei n. 12.529/2011) .................................72

2.4.2 Área de manifestação da eficácia preclusiva da coisa julgada material .......................74

2.4.2.1 As questões sujeitas à eficácia preclusiva da coisa julgada..............................79

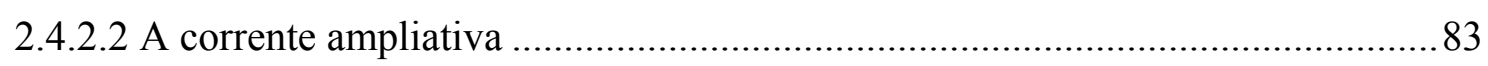

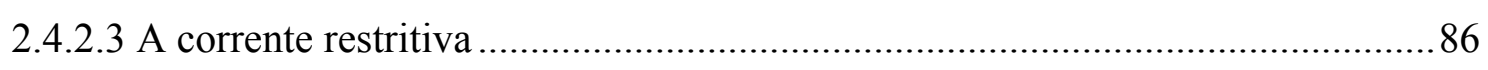

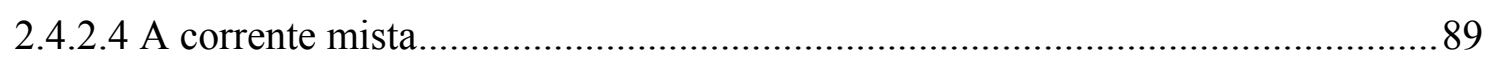

2.4.3 Marco temporal da eficácia preclusiva da coisa julgada: uma análise

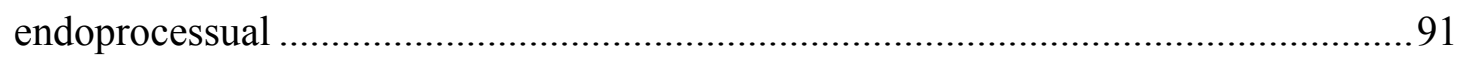

2.5 Os limites subjetivos da eficácia preclusiva da coisa julgada: autor, réu e terceiros ...........95

2.5.1 A eficácia da intervenção do assistente ................................................................... 99

2.5.2 A eficácia preclusiva da coisa julgada na tutela dos direitos transindividuais ........... 107 
2.6 Limites à eficácia preclusiva da coisa julgada

2.6.1 Eficácia preclusiva da coisa julgada e a ação rescisória

2.6.2 Eficácia preclusiva da coisa julgada em face do efeito preclusivo no cumprimento de sentença e da fase de liquidação de sentença.................................................................121

2.6.3 Eficácia preclusiva da coisa julgada dos embargos à execução........................................126

2.7 A principal função da eficácia preclusiva da coisa julgada............................................. 127

CONCLUSÃO

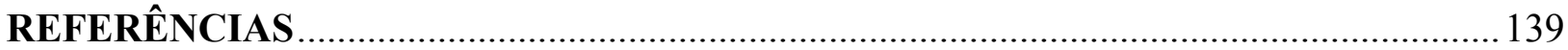




\section{INTRODUÇÃO}

O presente trabalho tem como finalidade o estudo do instituto da eficácia preclusiva da coisa julgada, com previsão no art. 508 do atual Código de Processo Civil brasileiro, que, por se tratar de um fenômeno processual de alta complexidade, exige tratamento específico, a partir dos conceitos dos institutos da preclusão e da coisa julgada material e formal. Além disso, o presente trabalho também tem como objetivo analisar a conformação legal a respeito do instituto e chegará à conclusão de que o Código de Processo Civil de 2015, por adotar dispositivo idêntico ao do Código de Processo Civil de 1973, manteve e ratificou a posição de que o alcance da eficácia preclusiva da coisa julgada tem limite na mesma causa de pedir proposta na inicial.

O presente trabalho mostra-se necessário e importante ante a obscuridade que ainda existe com relação a uma das vertentes da coisa julgada: a eficácia preclusiva da coisa julgada. Justamente pelo fato do Novo Código de Processo Civil reafirmar e nada acrescentar a respeito do conceito da eficácia preclusiva da coisa julgada, presente há mais de 40 anos no antigo Código de Processo Civil, o instituto ainda causa inúmeras dificuldades interpretativas, tanto na prática forense, como no âmbito acadêmico, justamente por conta da tênue linha que o separa dos institutos da preclusão e da coisa julgada.

Apesar de expressas definições em dispositivos legais específicos, na prática eles nem sempre são diferenciados, seja por falta de conhecimento mais profundo sobre os institutos, seja pela própria incerteza do que estaria incluído sob os efeitos da eficácia preclusiva da coisa julgada. Por ambas as razões, toda e qualquer contribuição para o aprofundamento na compreensão e aplicação deste instituto torna-se indispensável e se mostra valiosa na procura da perfeição na aplicação das normas.

Com o presente trabalho, procurar-se-á adentrar nas questões relativas à conceituação de cada instituto pertinente ao tema em debate na medida do necessário para diferenciá-los da eficácia preclusiva. Essa distinção se mostra fundamental para posterior análise pormenorizada do tema central do estudo.

Em primeiro lugar, é importante entender a razão de ser da eficácia preclusiva da coisa julgada, que reside na opção do ordenamento jurídico brasileiro em adotar a regra da eventualidade e um sistema rígido de preclusões. $\mathrm{O}$ ordenamento jurídico brasileiro, como é 
cediço, estabelece momentos próprios para que as partes apresentem suas alegações, sob pena de preclusão, e a inobservância de tais regras acarreta consequências. Que consequências são estas?

A partir do art. 508 do Código de Processo Civil, que trata especificamente da eficácia preclusiva da coisa julgada, passa-se a investigação analítica do mesmo, incluindo, por exemplo, a questão relativa à sua própria conceituação, quais são as questões sujeitas à eficácia preclusiva e quais são as que, somente a partir da própria coisa julgada, poderiam se tornar, igualmente, imutáveis.

Indispensável diferenciar de modo claro e com concepções bastante sustentáveis, o instituto da preclusão, da coisa julgada e da eficácia preclusiva. Todos os três institutos possuem um ponto em comum, de uma forma ou outra, impõe limitações ao direito de discutir em juízo questões ou pretensões. Todavia, os traços que os distinguem também são marcantes: o primeiro é verificado no desenvolvimento normal de qualquer processo; a coisa julgada material é uma qualidade que se agrega às sentenças de mérito, ao passo que a eficácia preclusiva faz surgir uma eficácia bloqueadora decorrente da coisa julgada material e tem por finalidade resguardar o resultado prático da demanda. Vê-se, portanto, que o objetivo da eficácia preclusiva é evitar qualquer tipo de insegurança jurídica com a propositura de nova demanda, com mesma causa de pedir e pedido da demanda anterior, no bojo da qual se proferiu decisão de mérito, cujo trânsito em julgado já se operou.

Demais disso, o estudo da coisa julgada não se limitará à sua natureza e função, tendo em vista ser indispensável a sua correta identificação na dinâmica processual, especialmente sob a ótica dos seus limites objetivos. Se observará neste trabalho a teoria adotada pelo ordenamento jurídico brasileiro sobre os limites objetivos da coisa julgada e como tal teoria se harmoniza com a eficácia preclusiva da coisa julgada.

O estudo do presente trabalho chega ao fim com análise minuciosa da própria eficácia preclusiva da coisa julgada em si, que tem por objetivo limitar as futuras discussões sobre causas de pedir e pedidos já debatidos — desde que entre as mesmas partes litigantes e relacionadas à específica causa de pedir trazida à apreciação do judiciário- pois, do contrário, as causas já decididas poderiam ser repropostas indefinidamente, tornando qualquer questão sujeita a uma enorme insegurança jurídica e a uma eterna rediscussão do objeto do processo (mérito) já julgado. 
Assim, justifica-se a presente dissertação como meio de se melhor estudar os reais efeitos — e como eles se dão— da eficácia preclusiva da coisa julgada, tendo em vista que sua compreensão pode gerar diversas consequências de ordem práticas. Como exemplo, no caso em que a parte ajuíza nova demanda, com mesma causa de pedir e pedido daquela em que foi proferida decisão transitada em julgado, tentando se valer de um argumento que, embora relevante à alteração do quanto decidido, tornou-se irrelevante por força dos efeitos da eficácia preclusiva da coisa julgada.

Justifica-se, também, a escolha do presente tema pela existência de divergência doutrinária e jurisprudencial quanto ao alcance processual dos efeitos da eficácia preclusiva da coisa julgada — v.g. há aqueles que entendem que a eficácia preclusiva da coisa julgada não impede a reformulação do mesmo pedido, desde que com base em outra causa de pedir, ainda que tal causa de pedir pudesse ter sido alegada na primeira ação, mas não o foi (corrente restritiva). Há outros que defendem posição diversa, ao alegar que tal instituto atinge todas as possíveis causas de pedir que pudessem servir de base ao pedido formulado, ou seja, a coisa julgada implicaria o julgamento de todas as causas de pedir que pudessem ter sido deduzidas, mas não foram (corrente ampliativa). Há ainda uma terceira corrente (mista) que foi no meio termos das correntes ampliativa e restritiva.

Apesar da constatação de que a maioria doutrinária encampa a interpretação mais restritiva do alcance da eficácia preclusiva da coisa julgada, isso não é suficiente para se dizer que o tema está pacificado. Isto porque, além de tal dissenso desafiar o tema desde a edição do Código de Processo Civil de 1973, com a edição do Novo Código de Processo Civil, nada mudou: o Código de Processo Civil de 2015 manteve a redação que gerou tanta polêmica a respeito da eficácia preclusiva da coisa julgada.

Por outro lado, o Novo Código de Processo Civil, em seu art. 1.072, inc. VI, fez por bem em revogar o art. 98, $\S 4^{\circ}$, da Lei n. 12.529/2011 —que trazia uma exceção ao acolher a corrente ampliativa sobre o tema-, reforçando, assim, sistematicamente a limitação da eficácia preclusiva da coisa julgada à mesma causa de pedir (corrente restritiva).

Diante de tudo isso, o foco principal do presente trabalho é tentar harmonizar todos os institutos correlatos e necessários à correta interpretação e identificação dos efeitos da eficácia preclusiva da coisa julgada, para se analisar, ao final, suas repercussões práticas no ordenamento jurídico brasileiro. 


\section{CONCLUSÃO}

Ao longo da dissertação do presente trabalho, foram feitas conclusões parciais a respeito de cada tema na tentativa de se traçar a ligação entre cada instituto estudado e a eficácia preclusiva da coisa julgada. Seguem abaixo, as considerações finais sobre todo o estudo realizado.

O ordenamento jurídico brasileiro adotou um sistema rígido de preclusões, que prevê a necessidade de as partes respeitarem os limites cronológicos estabelecidos no sistema normativo para a prática de atos processuais, pois, se não observada a prática do ato no tempo e modo devidos, apena-se a parte com a perda do direito de praticar o ato. Tal penalidade se traduz no instituto da preclusão, que serve para regular a marcha do processo, impulsionar o procedimento e impedir que ele retroceda. A preclusão tem como finalidade primordial conferir efeito preclusivo a certas situações processuais, a fim de não só garantir a segurança jurídica aos jurisdicionados, mas também limitar a tramitação de determinado processo no tempo. Tal efeito preclusivo será mais restrito quando incidente somente dentro do processo e, mais amplo, quando incidente fora do processo.

Até a prolação da decisão saneadora, especificamente com a designação da audiência de instrução e julgamento, o processo se desenvolve por etapas sucessivas, que são marcadas pela aplicação rigorosa da preclusão e do correlato princípio da eventualidade, este último, está ligado ao ônus das partes afirmarem todas as suas alegações em um único momento processual (autor, na inicial e réu, na contestação).

A regra da eventualidade para o réu é mais rígida, tendo em vista que pode o autor apresentar, em outro processo, novo pedido sobre os mesmos fatos apresentados em processo anterior, se alterada a causa de pedir. Já o réu, caso não apresente, em sua contestação, resposta suficientemente eficiente para afastar todas as pretensões deduzidas pelo autor na inicial, não poderá, depois de resolvida a lide, ajuizar uma nova ação sobre os mesmos fatos valendo-se de qualquer defesa relacionada a estes mesmos fatos, que deveria ter sido apresentada oportunamente em sua defesa.

De tais considerações, traçou-se importante raciocínio sobre a regra da eficácia preclusiva da coisa julgada, que impede que o autor deduza causa de pedir em nova ação se apenas as argumentações forem diversas, mas se houver nova causa de pedir é permitida a 
dedução de nova demanda, uma vez que a nova causa de pedir escapa da proteção atingida pela tríplice identidade. Já no que se refere às alegações do réu, são todas elas repelidas, tendo sido elas deduzidas ou não, pois a eficácia preclusiva da coisa julgada impede que o réu busque o judiciário com fundamento em qualquer outra argumentação que poderia ter servido de base para sua defesa na primeira demanda.

Com o transito em julgado, a decisão adquire sua imutabilidade. Referida imutabilidade, que é a autoridade da coisa julgada, gera um efeito negativo, que consiste na impossibilidade de se discutir qualquer questão já decidida dentro do processo encerrado e, um efeito positivo, que consiste em vincular o juiz que eventualmente possa, em um futuro processo, ir em sentido contrário ao quanto decidido no processo anterior com transito em julgado. A autoridade da coisa julgada somente produz efeitos para fora do processo quando formada a coisa julgada material. Diante disto, quando se põe fim ao processo por meio de uma decisão que não decidiu o mérito e que, portanto, opera tão somente a coisa julgada formal, não há que se falar na proteção —e efeitos dela decorrentes (eficácia preclusiva) — da coisa julgada material.

A autoridade da coisa julgada material encontra seus limites objetivos no pedido, delimitado pela causa de pedir (questão principal da lide). Todas as demais questões resolvidas ao longo do processo e analisadas na fundamentação da sentença, que constituam premissas necessárias à conclusão, apesar de antecedente lógico para o julgamento final do mérito, não ficam abrangidas pelos limites objetivos da coisa julgada (exceções trazidas nos parágrafos do art. 503 do atual Código de Processo Civil).

A eficácia preclusiva da coisa julgada existe justamente para proteger a autoridade da coisa julgada, indo além de seus limites objetivos, estendendo-a a todas as questões decididas (diversas da decisão sobre o mérito, porque esta decisão adquire a autoridade da coisa julgada), bem como a toda matéria que a parte poderia opor tanto ao acolhimento quanto à rejeição do pedido (CPC, art. 505, caput, c/c art. 508).

Assim, as questões que não são abrangidas pela coisa julgada, cujos seus limites objetivos não alcançam, o são pela eficácia preclusiva da coisa julgada, desde que relacionadas à mesma causa de pedir. Importante relembrar que, não somente as questões prejudiciais como também todas as demais questões de fato e de direito sobre as quais deve haver pronunciamento do juiz, para se decidir o mérito da causa, constituem antecedentes lógicos e, por isso, premissas necessárias da sentença. Tais questões podem, portanto, ser 
deduzidas em novo processo, desde que seu objeto seja diverso do anterior. Todavia, se este novo processo visar a modificar (seja para diminuir ou extinguir) a sentença passada em julgado anterior, não poderão tais questões ser novamente deduzidas, por força da eficácia preclusiva da coisa julgada. Novas questões (supervenientes à decisão passada em julgado) constituem nova causa de pedir e, por isso, não são atingidas pelo efeito preclusivo.

Por isso, o instituto da eficácia preclusiva da coisa julgada deve necessariamente ser estudado em conjunto com a autoridade da coisa julgada e seus limites objetivos, tendo em vista que para se saber os limites da eficácia preclusiva é preciso saber exatamente aquilo que foi decidido no dispositivo da decisão de mérito.

Assim, é possível afirmar que a eficácia preclusiva da coisa julgada nasceu para proteger a imutabilidade do julgado, na medida em que considera que todas as questões que foram e poderiam ter sido deduzidas em juízo são afastadas, tornando irrelevante o que não foi alegado, porque se mistura com o objeto do processo que foi imunizado.

A eficácia preclusiva da coisa julgada tem como finalidade, pois, proteger a coisa julgada formada em determinado processo, quando existir, em processo diverso, a potencialidade de violar sua autoridade, por meio da tentativa de uma das partes de trazer, neste novo processo, argumentos (deduzidos ou dedutíveis da demanda anterior) relacionados à mesma causa de pedir.

Verifica-se, assim, que a análise da incidência da eficácia preclusiva da coisa julgada está centrada em se verificar se há ou não nova causa de pedir ou apenas novos argumentos da mesma causa de pedir. Se houver nova causa de pedir, não há que se falar no impedimento trazido pela eficácia preclusiva da coisa julgada. Tal raciocínio se aplica quando se está a analisar a posição do autor. Se analisado o instituto do ponto de vista do réu, a incidência da eficácia preclusiva da coisa julgada se dá pela regra da eventualidade e, assim, encampa todas as alegações de defesa possíveis. Daí nasceram três correntes sobre a incidência da eficácia preclusiva: a ampliativa, a restritiva e a mista. Neste trabalho, assim como o faz o Código de Processo Civil atual e a doutrina majoritária, defende-se a corrente restritiva, que sustenta a ideia de que a eficácia preclusiva fica limitada à específica causa de pedir trazida na demanda pelo autor.

Demais disso, não se pode equiparar a eficácia preclusiva da coisa julgada com o efeito de um julgamento implícito de questões não apreciadas pelo magistrado ou não suscitadas pela 
parte quando o poderiam ter sido, sob pena de se dar a entender que tais questões ficariam, também, imunizadas pela autoridade da coisa julgada, o que é totalmente inadequado.

A eficácia preclusiva da coisa julgada atinge autor, réu e terceiros. No que diz respeito aos terceiros há certas peculiaridades que precisam ser estudadas antes de se concluir se o terceiro ficará ou não atingido pela eficácia preclusiva da coisa julgada. Nos casos de intervenção de terceiros pelo meio da assistência simples, por exemplo, se está diante da eficácia da intervenção do assistente, que impede que o terceiro discuta, em processo ulterior, a justiça da decisão passada em julgada no processo em que figurou como assistente. Tal efeito, portanto, difere-se da eficácia preclusiva da coisa julgada tradicional.

Existe também a eficácia preclusiva da coisa julgada no processo coletivo, que embora possa ser objeto de monografia exclusiva, foi tratada de forma concisa nesta dissertação, aonde se demonstrou que possui contornos um tanto diversos da eficácia preclusiva da coisa julgada incidente nos processos individuais. Nas hipóteses de improcedência da ação coletiva por insuficiência de provas, seja nos direitos difusos e coletivos, seja nos direitos individuais homogêneos, tendo em vista a formação tão somente de coisa julgada formal, não há que se falar em eficácia preclusiva — uma vez que esta é um instrumento somente da coisa julgada material. Caso o comando da sentença seja desfavorável aos indivíduos lesados, ainda quando formada a coisa julgada material, também não é o caso de aplicação da técnica da eficácia preclusiva aos interessados, já que inexiste a incidência da eficácia preclusiva da coisa julgada no processo coletivo, quando a decisão é desfavorável aos interessados não intervenientes no processo. Isto porque a eficácia preclusiva da coisa julgada, assim como a coisa julgada material, não impede o ajuizamento de ações individuais, onde seja renovada a discussão sobre as mesmas questões de fato e de direito já examinadas no julgado coletivo, mesmo que a conclusão a seu respeito seja diversa.

Demais disso, é por meio da eficácia preclusiva da coisa julgada material que, excetuando-se a via rescisória e demais teorias da relativização da sentença, fíca obstaculizada a rediscussão de qualquer questão que se tornou imutável por força da coisa julgada material. Tal instituto é de enorme importância para a solução das questões práticas, tendo em vista que como desdobramento da coisa julgada, impede a rediscussão não só daquilo que efetivamente foi suscitado (o deduzido), mas também daquilo que poderia ter sido discutido ao longo da fase cognitiva do processo, mas não o foi (o deduzível). Importante, portanto, o papel da eficácia preclusiva da coisa julgada, haja vista que é por meio dela que todas as questões, sejam elas deduzidas ou deduzíveis, que 
formam as premissas necessárias da decisão final, considerar-se-ão decididas e estabilizadas, trazendo segurança às decisões emanadas do poder judiciário no processo, enquanto mecanismo estatal de pacificação de conflitos.

Portanto, a relevância e incidência do instituto da eficácia preclusiva da coisa julgada material se dão somente se existir em um novo processo a potencialidade de se ofender a coisa julgada formada no passado, porque ela atingirá todas as questões de fato e de direito, que poderiam ter sido discutidas e decididas no processo, mas não foram, desde que, de alguma maneira, tenham o condão de influir no julgamento do processo ulterior. Ela funciona como uma verdadeira camada protetora a resguardar a imutabilidade da coisa julgada material formada no processo. 


\section{REFERÊNCIAS}

ALVIM, Arruda. Ação declaratória incidental. Revista de Processo, São Paulo, n. 20, p. 10, out./dez. 1980.

. Manual de direito processual civil. 6. ed. São Paulo: Revista dos Tribunais, 1997.

v. 1.

ALVIM, Thereza. Questões prévias e os limites objetivos da coisa julgada. São Paulo: Revista dos Tribunais, 1977.

ARAGÃO, Egas Dirceu Moniz de. Preclusão (processo civil). In: SANEAMENTO do processo: estudos em homenagem ao Prof. Galeno Lacerda. Porto Alegre: Sérgio Antonio Fabris Editor, 1989.

. Sentença e coisa julgada: exegese do Código de Processo Civil (arts. 444 a 575). Rio de Janeiro: Aide, 1992.

ASSIS, Araken de. Cumulação de ações. 2. ed. São Paulo: Revista do Tribunais, 1995.

- Reflexões sobre a eficácia preclusiva da coisa julgada. Ajuris: Revista da Associação dos Juízes do Rio Grande do Sul, Porto Alegre, v. 15, n. 44, p. 25-44, nov. 1988.

BARBI, Celso Agrícola. Comentários ao Código de Processo Civil. 9. ed. Rio de Janeiro: Forense, 1994. v. 1.

. Da preclusão no processo civil. Revista Forense, Rio de Janeiro, ano 52, v. 158, mar./abr. 1955.

BARBOSA, Antônio Alberto Alves. Da preclusão processual civil. 2. ed. rev. e atual. 2. tir., com notas remissivas à legislação processual vigente por Antonio Cezar Peluso. São Paulo: Revista dos Tribunais. 1994.

BEDAQUE, José Roberto dos Santos. Direito e processo: influência do direito material sobre o processo. 2. ed. São Paulo: Malheiros Ed., 1995.

Os elementos objetivos da demanda examinados à luz do contraditório. In: CRUZ E TUCCI, José Rogério; BEDAQUE, José Roberto dos Santos (Coords.). Causa de pedir e pedido no processo civil. São Paulo: Revista dos Tribunais, 2002.

. Efetividade do processo e técnica processual. São Paulo: Malheiros Ed., 2006.

BONATO, Giovanni. Algumas considerações sobre coisa julgada no novo Código de Processo Civil brasileiro: limites objetivos e eficácia preclusiva. In: GRINOVER, Ada Pellegrini et al. O novo Código de Processo Civil: questões controvertidas. São Paulo: Atlas, 2015. 
BUENO, Cassio Scarpinella. Curso sistematizado de direito processual civil: procedimento comum: ordinário e sumário. 2. ed. rev., atual. e ampl. São Paulo: Saraiva, 2009. v. 2, t. 1.

2, t. 1 .

. Curso sistematizado de direito processual civil. 4. ed. São Paulo: Saraiva, 2010. v.

CABRAL, Antonio do Passo. Coisa julgada. In: WAMBIER, Teresa Arruda Alvim; DIDIER JUNIOR, Fredie; TALAMINI, Eduardo; DANTAS, Bruno (Coords.). Breves comentários ao novo Código de Processo Civil. São Paulo: Revista dos Tribunais, 2015.

. Coisa julgada e preclusões dinâmicas: entre continuidade, mudança e transição de posições processuais estáveis, Salvador: JusPODIVM, 2013.

CARNELUTTI, Francesco. Instituições do processo civil. Tradução de Adrián Sotero de Witt Batista. Campinas: Servanda, 1999. v. 1.

. Lezioni di diritto processuale civile. Padova: Cedam, 1986. v. 4.

CARVALHO, Milton Paulo de. Do pedido no processo civil. Porto Alegre: Sérgio Antonio Fabris Editor, 1992.

CHIOVENDA, Giuseppe. Instituições de direito processual civil. Tradução do original italiano por Paolo Capitanio; com anotações do prof. Enrico Tullio Liebman. Campinas: Brookseller, 1998. v. 1.

CINTRA, Antônio Carlos de Araújo; GRINOVER, Ada Pellegrini; DINAMARCO, Cândido Rangel. Teoria geral do processo. São Paulo: Malheiros Ed., 1997.

CINTRA, Lia Carolina Batista. Intervenção de terceiro por ordem do juiz: a intervenção iussu iudicis no processo civil. São Paulo: Revista dos Tribunais, 2017.

COUTURE, Eduardo J. Fundamentos do direito processual civil. Florianópolis: Conceito Editorial, 2008.

CRUZ E TUCCI, José Rogério. A causa petendi n-o processo civil. 2. ed. rev. atual. e ampl. São Paulo: Revista dos Tribunais, 2001.

. A causa petendi no processo civil. 3 ed. São Paulo: Revista dos Tribunais, 2009.

. Limites subjetivos da eficácia da sentença e da coisa julgada nas ações coletivas. Revista de Processo, São Paulo, v. 32, n. 143, p. 42-64, jan. 2007.

. Limites subjetivos da eficácia da sentença e da coisa julgada civil. São Paulo: $\overline{\text { Revista }}$ dos Tribunais, 2006.

; BEDAQUE, Roberto dos Santos. Causa de pedir e pedido no processo civil: questões polêmicas. São Paulo: Revista dos Tribunais, 2002.

DIDIER JR., Fredie. Comentários ao art. 508 do CPC/2015. In: CABRAL, Antônio do Passo; CRAMER Ronaldo (Coords.). Comentários ao novo Código de Processo Civil. Rio de Janeiro: Forense, 2015. 
DIDIER JR., Fredie. Curso de direito processual civil. 8. ed. Salvador: JusPodvim, 2013. v. 2.

; BRAGA, Paula Sarno; OLIVEIRA, Rafael. Curso de direito processual civil. 7. ed. Salvador: JusPodivm, 2012. v. 2.

DINAMARCO, Cândido Rangel. Instituições de direito processual civil. 2. ed. São Paulo: Malheiros Ed., 2002. v. 2.

. Instituições de direito processual civil. 2. ed. São Paulo: Malheiros Ed., 2002. v. 3.

. Instituições de direito processual civil. 6. ed. São Paulo: Malheiros Ed., 2009. v. 3.

. Intervenção de terceiros. 5. ed. São Paulo: Malheiros Ed., 2009.

GARJARDONI, Fernando da Fonseca; DELLORE, Luiz; ROQUE, André Vasconcelos; OLIVEIRA JUNIOR, Zulmar Duarte de. Processo de conhecimento e cumprimento de sentença comentários ao CPC de 2015. São Paulo: Método, 2016.

GARCIA, Gustavo Filipe Barbosa. Considerações sobre a eficácia preclusiva da coisa julgada. Revista de Processo, São Paulo, ano 30, n. 130, p. 49-63, dez. 2005.

GIANNICO, Maurício. A preclusão no direito processual civil brasileiro. 2. ed. rev. e atual. São Paulo: Saraiva, 2007.

GIDI, Antonio. Coisa julgada e litispendência em ações coletivas. São Paulo: Saraiva, 1995.

; TESHEINER, José Maria Rosa; PRATES, Marília Zanella. Limites objetivos da coisa julgada no projeto de Código de Processo Civil: reflexões inspiradas na experiência norte-americana. Revista de Processo, São Paulo, n. 194, abr. 2011.

GRECO FILHO, Vicente. Direito processual civil. 18. ed. São Paulo: Saraiva, 2007. v. 2.

GRINOVER, Ada Pellegrini. Considerações sobre os limites objetivos e a eficácia preclusiva da coisa julgada. Revista Síntese de Direito Civil e Processual Civil, Porto Alegre, v. 1, n. 1, set,/out. 1999.

. Os limites objetivos e a eficácia preclusiva da coisa julgada. In: GRINOVER, Ada Pellegrini. O processo: estudos e pareceres. 2. ed. rev. e ampl. São Paulo: DPJ Ed., 2009.

2015.

et al. O novo Código de Processo Civil: questões controvertidas. São Paulo: Atlas,

GUIMARÃES, Luiz Machado. Estudos de direito processual civil. Rio de Janeiro; São Paulo: Jurídica e Universitária, 1969.

Preclusão, coisa julgada, efeito preclusivo. In: GUIMARÃES, Luiz Machado.

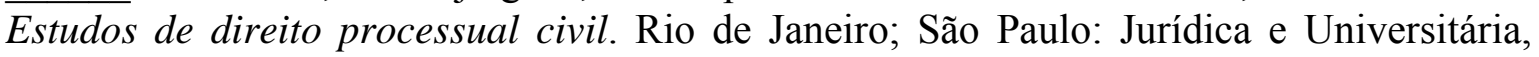
1969. 
LEONEL, Ricardo de Barros. Causa de pedir e pedido: o direito superveniente. São Paulo: Método, 2006.

. Manual do processo coletivo. São Paulo: Revista dos Tribunais, 2002.

LIEBMAN, Enrico Tullio. Eficácia e autoridade da sentença e outros escritos sobre a coisa julgada. Trad. de Alfredo Buzaid, Benvido Aires e Ada Pellegrini Grinover. 3. ed. Rio de Janeiro: Forense, 1984.

. Eficácia e autoridade da sentença (e outros escritos sobre a coisa julgada). 4. ed. Trad. Alfredo Buzaid e Benvindo Aires. Notas relativas ao direito brasileiro vigente de Ada Pellegrini Grinover. Rio de Janeiro: Forense, 2006.

. Estudos sobre o processo civil brasileiro. Campinas: Bestbook, 2001.

LIMA, Alcides de Mendonça. Comentários ao Código de Processo Civil. 5. ed. Rio de Janeiro: Forense, 1987.

LOPES, Bruno Vasconcelos Carrilho. A extensão da coisa julgada às questões apreciadas na motivação da sentença. Revista de Processo, São Paulo, ano 38, v. 216, p. 431-438, fev. 2013.

. Limites objetivos e eficácia preclusiva da coisa julgada. São Paulo: Saraiva, 2012. (Coleção Theotonio Negrão).

MANCUSO, Rodolfo de Camargo. Coisa julgada, "collateral stoppel” e eficácia preclusiva "secundum eventum litis". Revista dos Tribunais, ano 75, v. 608, p. 23-33, jun. 1986.

. Jurisdição coletiva e coisa julgada: teoria geral das ações coletivas. 2. ed. São Paulo: Revista dos Tribunais, 2008.

MARCATO, Antonio Carlos. Preclusões: limitação ao contraditório? Revista de Processo, São Paulo, ano 5, n. 17, p. 105-114, jan./mar. 1980.

MARINONI, Luiz Guilherme. Coisa julgada inconstitucional: a retroatividade da decisão de (in)constitucionalidade do STF sobre a coisa julgada. A questão da relativização da coisa julgada. 2. ed. rev. e atual. São Paulo: Revista dos Tribunais, 2010. $\overline{\text { out. } 2011 .}$.

Sobre a eficácia preclusiva da coisa julgada. Soluções Práticas, v. 1, p. 491-517,

MARQUES, José Frederico. Instituições de direito processual civil. Campinas: Millennium, 1999.

. Instituições de direito processual civil. ed. rev., atual. e compl. por Ovídio Rocha Barros Sandoval. Campinas: Millennium, 2000. v. 2, 3 e 5.

. Manual de direito processual civil. São Paulo: Saraiva, 1982. v. 3.

MENDES, João de Castro. Limites objetivos do caso julgado em processo civil. Lisboa: Ática, 1968. 
MESQUITA, José Ignácio Botelho de. A coisa julgada. Rio de Janeiro: Forense, 2004.

MIRANDA, Francisco Cavalcanti Pontes de. Comentários ao Código de Processo Civil. 5. ed. Rio de Janeiro: Forense, 1996. t. 1.

MOREIRA, José Carlos Barbosa. Ainda e sempre a coisa julgada. In: WAMBIER, Teresa Arruda Alvim; WAMBIER, Luiz Rodrigues (Orgs.). Doutrinas essenciais de processo civil. São Paulo: Revista dos Tribunais, 2011. (Coleção Doutrinas Essenciais; v. 6).

. Coisa julgada e declaração. In: MOREIRA, José Carlos Barbosa. Temas de direito processual. São Paulo: Saraiva, 1977.

. A eficácia preclusiva da coisa julgada material no sistema do processo civil brasileiro. In: MOREIRA, José Carlos Barbosa. Temas de direito processual: primeira série. São Paulo: Saraiva, 1988.

. Eficácia da sentença e autoridade da coisa julgada. Revista de Processo, São Paulo, ano 9, n. 34, abr./jun. 1984.

. Questões prejudiciais e a coisa julgada. Revista de Direito da Procuradoria Geral do Estado da Guanabara, Rio de Janeiro, v. 16, p. 159-268, 1967.

NERY JÚNIOR, Nelson. Eficácia preclusiva da coisa julgada. Questão prejudicial [Parecer]. Revista de Processo, São Paulo, ano 13, n. 51, p. 164-167, jul./set. 1988.

- Princípios do processo na Constituição Federal: processo civil, penal e administrativo. 9. ed. São Paulo: Revista dos Tribunais, 2009.

; NERY, Rosa Maria de Andrade. Código de Processo Civil comentado e legislação extravagante. 10 ed. São Paulo: Revista dos Tribunais, 2007.

Revista dos Tribunais, 2016.

. Código de Processo Civil comentado. 16. ed. rev. ampl. São Paulo:

NUNES, João Batista Amorim de Vilhena. Da eficácia preclusiva da coisa julgada (reconstruindo a interpretação do art. 474, do CPC). 2010. Tese (Doutorado) Programa de Pós-Graduação em Direito, da Faculdade de Direito da Universidade de São Paulo, São Paulo, 2010.

PEREIRA, Guilherme Setoguti J. Inconstitucionalidade na nova lei do CADE. Migalhas, 16 maio 2012. Disponível em: <http://www.migalhas.com.br/dePeso/16,MI155555,21048Inconstitucionalidade+na+nova+lei+do+Cade>. Acesso em: 31 mar. 2018.

PINTO, Junior Alexandre Moreira. Sistemas rígidos e flexíveis: A questão da estabilização da demanda. In: CRUZ E TUCCI, José Rogério; BEDAQUE, José Roberto dos Santos (Org.). Causa de pedir e pedido no processo civil: (causas polêmicas). São Paulo: Revista dos Tribunais, 2002.

PORTO, Sérgio Gilberto. Coisa julgada civil. 3. ed. São Paulo: Revista dos Tribunais, 2006. 
PORTO, Sérgio Gilberto. Sobre o propósito e o alcance do art. 474 do CPC. Revista Síntese de Direito Civil e Processual Civil, Porto Alegre, v. 1, n. 1, p. 39-47, set./out. 1999.

PROTO PISANI. Andrea. Lezioni di diritto processuale. 5. ed. Napoli: Jovene. 2006.

ROCCO, Ugo. L'autorità dela cosa giudicata e i suoi limiti soggettivi. Roma: Athaeneum, 1917. t. 1.

RODRIGUES, Marcelo Abelha. Reflexos do direito material do ambiente sobre o instituto da coisa julgada: in utilibus, limitação territorial, eficácia preclusiva da coisa julgada e coisa julgada rebus sic stantibus. De Jure: Revista jurídica do Ministério Público do Estado de Minas Gerais, Belo Horizonte, n. 7, p. 87-92, jul./dez. 2006.

RODRIGUES, Walter Piva. Coisa julgada tributária. São Paulo: Quartier Latin, 2008.

SÁ, Renato Montans de. Eficácia preclusiva da coisa julgada. São Paulo: Saraiva, 2011. (Coleção direito e processo. Coordenador Cassio Scarpinella Bueno).

SANTOS, Ernane Fidélis dos. Manual de direito processual civil: processo de conhecimento. 12. ed. São Paulo: Saraiva, 2007. v. 1.

SANTOS, Moacyr Amaral. Primeiras linhas de direito processual civil. 24. ed. São Paulo: Saraiva, 2008. v. 2.

SCHWAB, Karl Heinz. El objeto litigioso en el proceso civil. Trad. de Tomas A. Banzhaf. Buenos Aires: Ejea, 1968.

SICA, Heitor Vitor Mendonça. Preclusão processual civil. 2. ed. São Paulo: Atlas, 2008. (Coleção Atlas de Processo Civil. Coord. Carlos Alberto Carmona).

SILVA, Ovídio A. Baptista da. Curso de processo civil: processo de conhecimento. 7. ed. Rio de Janeiro: Forense, 2006. v. 1.

. Sentença e coisa julgada. 4. ed. Rio de Janeiro: Forense, 2003.

TALAMINI, Eduardo. Coisa julgada e constituição: limites da "relativização" da coisa julgada. 2004. Tese (Doutorado) - Programa de Pós-Graduação em Direito, da Faculdade de Direito da Universidade de São Paulo, São Paulo, 2004.

- Coisa julgada e sua revisão. Coisa julgada e Constituição. O regime infraconstitucional da coisa julgada. A ação rescisória e outros meios rescisórios típicos. Os limites da revisão atípica ('relativização') da coisa julgada. As sentenças inexistentes. São Paulo: Revista dos Tribunais, 2005.

TEIXEIRA, Guilherme Freire de Barros. O princípio da eventualidade no processo civil. São Paulo: Revista dos Tribunais, 2005. (Coleção temas atuais de direito processual civil; v. 10).

TESHEINER, José Maria Rosa. A eficácia da sentença e a coisa julgada no processo civil. São Paulo: Revista dos Tribunais, 2002. 
TESHEINER, José Maria Rosa; THAMAY, Rennan Faria Krüger, Teoria geral do processo: em conformidade com o novo CPC. 2. ed. rev. atual e ampl. Rio de Janeiro: Forense, 2016.

THAMAY, Rennan Faria Krüger, A estabilidade das decisões no controle de constitucionalidade abstrato. São Paulo: Almedina, 2016.

THEODORO JR., Humberto. Curso de direito processual civil: teoria geral do direito processual civil e processo de conhecimento. 50. ed. Rio de Janeiro: Forense, 2009. v. 1. 23, jul. 2000 .

A preclusão no processo civil. Revista Jurídica, Porto Alegre, v. 48, n. 273, p. 5-

WAMBIER, Luiz Rodrigues. Sentença civil: liquidação e cumprimento. 3. ed. São Paulo: Revista dos Tribunais, 2006.

WAMBIER, Teresa Arruda Alvim. Omissão judicial e embargos de declaração. São Paulo: Revista dos Tribunais, 2005.

. O que é abrangido pela coisa julgada no direito processual civil brasileiro: a norma vigente e as perspectivas de mudança. Revista de Processo, São Paulo, ano 39, n. 230, p. 75-89, abr. 2014.

; MEDINA, José Miguel Garcia. O dogma da coisa julgada: hipóteses de relativização. São Paulo: Revista dos Tribunais, 2003.

ZUFELATO, Camilo. Coisa julgada coletiva. São Paulo: Saraiva, 2011. 